\title{
Immunization competence retention in medical students: a comparation between conventional lectures and lectures with simulations method
}

\author{
Hartono Gunardi ${ }^{1}$, Rini Sekartini ${ }^{1}$, Retno Asti Werdhani ${ }^{2}$, Ardi Findyartini ${ }^{3}$, \\ Muhammad Arvianda Kevin Kurnia ${ }^{3}$
}

\begin{abstract}
Background Immunization is recognized as one of the strategies to reduce vaccine preventable diseases. Competency related to immunization are consequently important for medical students and the medical school needs to assure the competence acquisition.

Objective To assess competence related to immunization and its retention following lectures with simulations compared to lectures only.

Methods A quasi-experimental study was conducted to the $5^{\text {th }}$ year students of University of Indonesia Medical School during the Child Adolescent Health Module in 2012-2013. The intervention group had lectures with simulations and the control group had lectures only. Immunization knowledge was assessed with a 30 multiple choice question (MCA) items performed before and after the module. Competence retention was assessed by MCQ (knowledge) and OSCE (skills) 2-6 months afterwards.

Results Sixty eight subjects for each group with similar characteristics were analyzed. There was significant difference after module MCQ score between two groups. Competence retention in 2-6 months after module completion was better in intervention group, both for the knowledge (median MCQ score of 70.00 (range 37-93) vs. mean score of 58.01 (SD 12.22), respectively; $\mathrm{P}<0.001$ ) and skill (OSCE mean scores of 75.21 (SD 10.74) vs. 62.62 (SD 11.89), respectively; $\mathrm{P}<0.001$ ). Proportion of subjects in the intervention group who passed both the MCQ and OSCE were also significantly greater.

Conclusion Lectures with simulations are proved to be more effective in improving medical students' immunization competence as well as its retention compared to lectures only approach. [Paediatr Indones. 2015;55:339-44].
\end{abstract}

Keywords: immunization, knowledge, skill, competence, simulation, retention
I mmunization is one of the primary prevention that was proven effective to halt the transmission of contagious diseases. ${ }^{1}$ Knowledge and procedural skills achieved by health professionals, especially medical doctors, are important to deliver immunization program properly. Medical students therefore must have immunization competence, as they will implement immunization program in the community soon after they were graduated. The lack of time due to tight schedule and minimum chances to practice during their clerkship might be an obstacle for students to get proper knowledge and sufficient immunization competence, therefore simulation methods might be the answer to the problem.

The objectives of this study were to compare immunization competences learning outcomes

This article was presented in free paper oral presentation session at The $6^{\text {th }}$ Jakarta Meeting on Medical Education, December 6, 2013.

From the Department of Child Health ${ }^{1}$, Community Medicine ${ }^{2}$, and Medical Education ${ }^{3}$, University of Indonesia Medical School/Dr. Cipto Mangunkusumo Hospital, Jakarta.

Reprint requests to: Dr. Hartono Gunardi, Child Development and Social Pediatrics Division, Department of Child Health, University of Indonesia Medical School/Dr. Cipto Mangunkusumo Hospital, Jl. Salemba 6, Jakarta 10340, Indonesia. Tel. +62-21-3160622. Fax.: +62-21-3907743. E-mail: hartono@ikafkui.net. 
following conventional lectures and lectures with simulations after module and evaluation of retention 2-6 months afterwards.

\section{Methods}

A quasi-experimental study was conducted among the $9^{\text {th }}$ and $10^{\text {th }}$ semester medical students of University of Indonesia Medical School in 2012-2013. Subjects were the first-taker of the Child and Adolescent Health Module (CAHM) at Child Health Department University of Indonesia Medical School/Dr. Cipto Mangunkusumo General, Jakarta. There were four group of students enrolled in CAHM during 20122013. The first two groups were assigned to control group and the last two groups assigned to intervention groups. The sample size in each group was calculated using mean comparison for independent samples. While $\alpha=0.05$, power $=0.80, s=17$ (assumption) and $\left(\mathrm{x}_{1}-\mathrm{x}_{2}\right)=5$, minimum sample size was 65 subjects in each group.

Both groups learned similar immunization topics based on the national immunization program, ${ }^{2,3}$ covering topics on infectious diseases particularly immunization preventable diseases, immunization schedule, catch-up immunization, immunization procedure, adverse events following immunization (AEFI), and parental vaccine refusal. The intervention group learned immunization related competences through conventional lectures and simulations using videos, simulation cases, various immunization procedure techniques, and practices on mannequin. Simulation cases included routine immunization schedule, catch-up immunization, contraindication of immunization, and booster immunization. The control group learned all of the topics only from conventional face-to-face lectures and tutorials.

A 30 item multiple-choice questions (MCQ) was administered to assess students' knowledge related to immunization topics as mentioned previously. The MCQ was administered before and after the students passed the CAHM for the intervention group and after the CAHM for the control group. Students' skill related to immunization was evaluated by objective structured clinical examination (OSCE). The OSCE consisted of three stations; there were preimmunization measures, immunization administration procedures, and post-immunization measures. The contents of OSCE questions were reviewed by four pediatric consultants for its validity, and were tested before OSCE examination. OSCE examiners were not aware of group of students. Each station was 5 minutes duration. Validity and reliability of OSCE were tested for each station. Cronbach's alpha was more than $60 \%$. This showed that the OSCE instrument was valid and reliable to measure immunization skills, and were able to be implemented in the future. Maximum scores of MCQ and OSCE were 100 and no penalty was applied for the wrong answers. Students' satisfaction survey was conducted for both groups at the end of the module. Retention of knowledge and skills were measured by MCQ and OSCE for both groups 2-6 months after module completion. The minimum passing score for MCQ and OSCE were 70.

This study was approved by The Health Research Ethics Committee University of Indonesia Medical School/Dr. Cipto Mangunkusumo Hospital, Indonesia.

\section{Results}

During year 2012-2013, there were 217 students enrolled in CAHM; 103 students were assigned to the control group and 114 students to the intervention group. Three students ( 2 of the control and 1 of the intervention group) were not included because absence at the time of enrollment. Fifty seven subjects (33 of control and 24 of intervention group) could not join the 2-6 months post-CAHM MCQ and/or OSCE. A total of 68 subjects of the control group and 89 subjects of the intervention group were eligible for further analysis (see Figure 1). Sixty eight subjects of the intervention group were randomly selected to be equal to 68 subjects of the control group for analysis.

The mean age of subjects was 22 (SD 1.1) years while the percentage of subject who was under 22 year old in the intervention and control groups were similar. The subjects was predominantly female in both groups. Table 1 shows that the characteristics of subjects in both groups did not differ significantly.

Intervention group showed significantly better post-CAHM MCQ $(\mathrm{P}<0.001)$ than control group (Table 2). The lectures and simulations learning 
Hartono Gunardi et al: Immunization competence retention in medical students

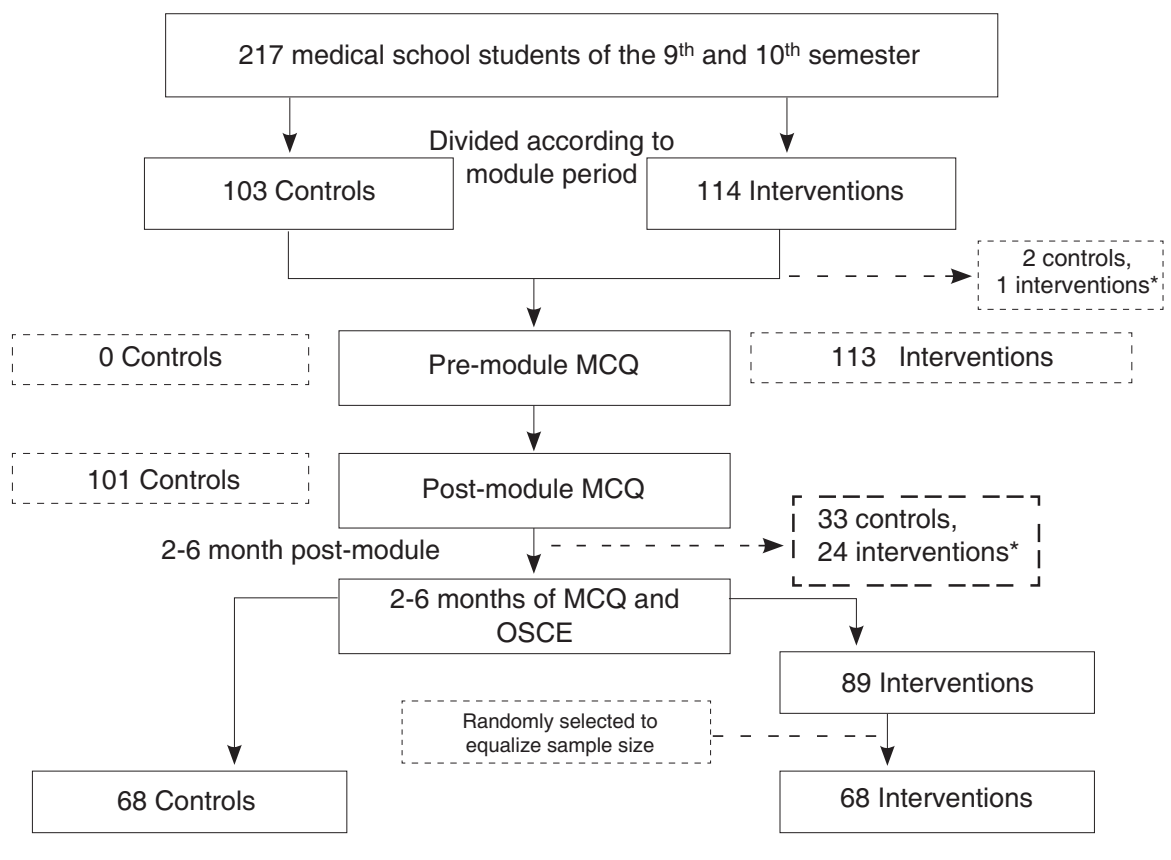

${ }^{*}$ Drop-out because not following one procedure

Figure 1. Flow diagram of the study

yielded significant $(\mathrm{P}<0.001)$ knowledge increment as assessed by pre- and post-CAHM MCQ with the median scores of 67 (range 38-87) and 80 (range 50-93), respectively. Immunization knowledge and skill retention 2-6 months post-CAHM were assessed by similar MCQ and OSCE. Retention scores, 2-6 months after CAHM for both MCQ as well as OSCE was significantly higher in the intervention compared to the control group $(\mathrm{P}<0.001)$. Intervention group achieved significantly higher OSCE scores in each

Table 1. Characteristics of subjects

\begin{tabular}{lcc}
\hline Characteristics & $\begin{array}{c}\text { Control group } \\
\mathrm{N}=68\end{array}$ & $\begin{array}{c}\text { Intervention group } \\
\mathrm{N}=68\end{array}$ \\
\hline $\begin{array}{ccc}\text { Age, } \mathrm{n}(\%) \\
<22 \text { years }\end{array}$ & $12(54.5)$ & $10(45.5)$ \\
$\geq 22$ years & $56(49.1)$ & $58(50.9)$ \\
Gender,n(\%) & & \\
Male & $31(55.4)$ & $25(44.6)$ \\
Female & $37(46.2)$ & $43(53.8)$ \\
\hline
\end{tabular}

Table 2. Results of MCQ and OSCE scores between the two groups

\begin{tabular}{lccc}
\hline & $\begin{array}{c}\text { Control group } \\
\text { Mean (SD) } \\
\mathrm{N}=68\end{array}$ & $\begin{array}{c}\text { Intervention group } \\
\text { Median (range) } \\
\mathrm{N}=68\end{array}$ & P value \\
\hline Pre-module MCQ & Not assessed & $67.00(33-87)$ & - \\
Post-module MCQ & $67.27(9.76)$ & $80.00(50-93)$ & $<0.001^{*}$ \\
MCQ 2-6 months post-CAHM & $58.01(12.22)$ & $70.00(37-93)$ & $<0.001^{*}$ \\
OSCE 2-6 months post-CAHM & $62.62(11.89)$ & $75.21(10.74)$ & $<0.001^{\text {** }}$ \\
\hline
\end{tabular}

${ }^{*}$ Mann-Whitney test, ${ }^{*}$ Independent T-test 
Hartono Gunardi et al: Immunization competence retention in medical students

station compared to the control group $(\mathrm{P}<0.001)$ (Table 3). administer various immunizations on a mannequin. Simulation eliminates risk to patients and students,

Table 3. Distribution of median scores of OSCE

\begin{tabular}{llcc}
\hline & Middle score & \multicolumn{2}{c}{ Total OSCE score } \\
\cline { 3 - 4 } & & $\mathrm{R}$ & $\mathrm{P}$ value \\
\hline Station 1 & 62.5 (range 12.5-100) & 0.737 & $<0.001^{*}$ \\
Station 2 & $79.0($ range 9.00-100) & 0.673 & $<0.001^{*}$ \\
Station 3 & $69.8($ SD 16.81) & 0.760 & $<0.001^{\star *}$ \\
\hline
\end{tabular}

Cronbach's alpha : 0.621

This study compared proportion of subjects who passed the test between the two groups. The intervention group had higher post-CAHM MCQ passing proportion than the control group, $64.1 \%$ vs. $35.9 \%$, respectively $(\mathrm{P}<0.001)$. Furthermore, at $2-6$ months post-CAHM the MCQ scores showed significant greater passing proportion $(75.9 \%)$ in the intervention group than the control group $(24.1 \%)(\mathrm{P}<0.001)$. Moreover, the intervention group had higher 2-6 months post-CAHM OSCE passing proportion than the control group $(78.8 \%$ and $24.2 \%$, respectively; $\mathrm{P}<0.001$ ).

\section{Discussion}

In medical education, different forms of simulation have been used successfully for decades. ${ }^{4}$ Simulation is both popular and effective, ${ }^{5}$ and it is used to teach knowledge, skills or competences. ${ }^{6}$ In undergraduate medical education, simulations can be applied in basic science, physical examination, and clinical clerkship. ${ }^{?}$

Immunization is an essential competence to be mastered by medical students as they will practice immunization after graduation or even earlier in community health centres during a public health module. Students of University of Indonesia Medical School were programmed to learn immunization in CAHM at the $9^{\text {th }}$ and $10^{\text {th }}$ semester. Immunization topics were used to be given by one-way lectures. Students were used to learn more about immunization during clinical clerkship in outpatient clinics, mostly by observation, and rarely had any opportunity to practice in administering it. By integrating simulation, immunization learning in University of Indonesia Medical School was improved to an active learning method. Students were able to solve common immunization problems in simulation-based cases and and allows repeated practice of skills. ${ }^{8}$

The essential component of competence are knowledge and skill. ${ }^{9}$ Immunization knowledge in this study was assessed by MCQ, which is the most widely used assessment and has more than 90\% reliability. ${ }^{10}$ Immunization skill was assessed by OSCE, which is one of suggested method assessment in clinical simulation. ${ }^{11}$ The OSCE also has a good reliability, approximately $80 \%$, however this examination is expensive and labor-intensive. ${ }^{10}$

This study showed simulation-based learning increased immunization knowledge and skill acquisition in the intervention group. There was significant differences between the two groups on MCQ and OSCE scores as well as in pre- and post-CAHM MCQ in the intervention group. The knowledge and skill increased acquisition by simulation-based learning was also found in various other procedures such as pediatric resuscitation. Cheng et al. found that students who learned management of pediatric resuscitation with simulation had better results in increased of knowledge and leadership performances. ${ }^{12}$ A cumulative metaanalysis of the outcomes of simulation-based education (SBE) reviewed the studies that compared the skill outcomes of SBE with those of no intervention. Of 28 studies, it was concluded that the evidence confirmed a quantitatively large effect of SBE. ${ }^{13}$

Human memory declines overtime, furthermore, forgetting depends on a number of factors such as the difficulty of the learned material and type of learning. Passive learning, such as reading, will be retained approximately $10 \%$ only, while active learning, such as simulation-based learning will be retained as much as $90 \% .^{7}$ This study showed that the intervention group had less decrement in immunization knowledge and skill than control group at 2-6 month after completing CAHM. Higher MCQ and OSCE 
scores in intervention group - the components of immunization competence - reflected better retention in immunization knowledge and skill. It provided an evidence to previous hypothesis that simulation may be of value in assisting in retention of learning. ${ }^{14}$ Study of simulation in cardiac arrest management also supported the results of this study. The subjects who were given simulation showed to have better adherence than those who received traditional learning method, and knowledge could be retained for 14 months with simulation learning. ${ }^{15}$ Study in central venous catheter insertion skills showed that retention of skill acquired by simulation based learning could be retained until one year. ${ }^{16}$

Longer retention is better for acquisition of competence as student will practice immunization after they are graduated. Sufficient immunization knowledge of physicians or vaccinators will be an essential and reliable source of information for parents. Physicians, who have vast immunization knowledge, will convince parents easier about the importance of immunization. ${ }^{17}$ This study assessed the immunizations's knowledge and skill retention until 2-6 month after completing the module, due to time constraint, subsequently, after graduation subjects would have internship in remote rural hospitals.

In this study, OSCE instrument was found to be not only valid but also reliable and OSCE as a form of exam that measures competences, can be integrated with simulation-based learning. Martin et al. stated that performances in an OSCE taken early in the clinical course strongly predict later clinical performance. ${ }^{18}$ Validity and reliability of OSCE in evaluating competence were also studied in acute pediatric management by multiple scenarios assessment. The study showed that valid and reliable measures of competence or performance could be obtained by using simulation. ${ }^{19}$

We conclude that simulation-based learning has successfully increased immunization knowledge and skill, as measured by MCQ and OSCE, during $9^{\text {th }}$ and $10^{\text {th }}$ semester in students of University of Indonesia Medical School better than by lectures only method. Simulation-based learning also improved the retention of immunization competence, which consist of knowledge and skill, 2-6 months after Child and Adolescent Health Module compared to conventional lectures. Passing rate of those who received simulation-based learning was also greater than those who got conventional lectures only. This study emphasize that simulation-based learning, especially in pediatric immunization, increase gaining and retention of knowledge and skill, both are the component of competence. This method would be useful in other medical schools to improve immunization competence acquisition. In the future, students are expected to have sustain best ability in applying immunization competence in clinical settings, and furthermore better immunization coverage, and lower child morbidity and mortality from immunization preventable diseases.

\section{Acknowledgements}

We acknowledged Director, subordinates of Health Professional Education Quality (HPEQ) and Dean of University of Indonesia Medical School that had given us generous support to conduct this research. This study was supported by Health Professional Education Quality, University of Indonesia Medical School No: 705c/PT02.M1.HPEQ/X/2012, October 25, 2012.

\section{Conflict of interest}

None declared

\section{References}

1. Orenstein W, Pickering L. Immunization practices. In: Kliegman RM, Behrman R, Jenson H, BF S, editors. Nelson textbook of pediatrics. $18^{\text {th }}$ ed. Philadelphia: Saunders; 2007. p. 1058-71.

2. Ismael S, Hadinegoro SR. Program imunisasi nasional. In: Ranuh I, Suyitno H, Hadinegoro SR, Kartasasmita CB, Ismoedijanto, Soedjatmiko, eds. Pedoman imunisasi di Indonesia. $4^{\text {th }}$ ed. Jakarta: Badan Penerbit Ikatan Dokter Anak Indonesia; 2011.p.39-46.

3. Ranuh I. Imunisasi : upaya pencegahan primer. In: Ranuh I, Suyitno H, Hadinegoro SR, Kartasasmita CB, Ismoedijanto, Soedjatmiko, editors. Pedoman imunisasi di Indonesia. $4^{\text {th }} \mathrm{ed}$. Jakarta: Badan Penerbit Ikatan Dokter Anak Indonesia; 2011. p. 2-9.

4. Bradley P. The history of simulation in medical education and possible future directions. Medical education. 
Hartono Gunardi et al: Immunization competence retention in medical students

2006;40:254-62.

5. Fraser K, Ma I, Teteris E, Baxter H, Wright B, McLaughlin K. Emotion, cognitive load and learning outcomes during simulation training. Medical education. 2012;46:1055-62.

6. Siebeck M, Schwald B, Frey C, Röding S, Stegmann K, Fischer F. Teaching the rectal examination with simulations: effects on knowledge acquisition and inhibition. Medical education. 2011;45:1025-31.

7. McQueen AA, Mitchell DL, Joseph-Griffin MA. "Not Little Adults": Pediatric considerations in medical simulation. DmDis Mon. 2011;57:780-8.

8. Maran NJ, Glavin RJ. Low- to high-fidelity simulation - a continuum of medical education? Medical education. 2003;37:22-8.

9. Fernandez N, Dory V, Ste-Marie L-G, Chaput M, Charlin B, Boucher A. Varying conceptions of competence: an analysis of how health sciences educators define competence. Medical education. 2012;4:357-65.

10. Wass V, Van der Vleuten C, Shatzer J, Jones R. Assessment of clinical competence. Lancet. 2001;357:945-9.

11. Cox M, Irby DM, Epstein RM. Assessment in medical education. New Engl J Med. 2007;356:387-96.

12. Cheng A, Hunt EA, Donoghue A, Nelson-McMillan $\mathrm{K}$, Nishisaki A, LeFlore J, et al. Examining pediatric resuscitation education using simulation and scripted debriefing: a multicenter randomized trial. JAMA Pediatr.
2013;167:528-36.

13. Cook DA. How much evidence does it take? A cumulative meta-analysis of outcomes of simulation-based education. Medical education. 2014;48:750-60.

14. Weller JM. Simulation in undergraduate medical education: bridging the gap between theory and practice. Medical education. 2004;38:32-8.

15. Wayne DB, Didwania A, Feinglass J, Fudala MJ, Barsuk JH, McGaghie WC. Simulation-based education improves quality of care during cardiac arrest team responses at an academic teaching hospital: a case-control study. Chest. 2008;133:5661.

16. Barsuk JH, Cohen ER, McGaghie WC, Wayne DB. Longterm retention of central venous catheter insertion skills after simulation-based mastery learning. Acad Med. 2010;85:S9S12.

17. Carr J, Martin M, Clements C, Ritchie P. Behavioural factors in immunization. Behavioural Science Learning Modules. 2000:1-10.

18. Martin IG, Jolly B. Predictive validity and estimated cut score of an objective structured clinical examination (OSCE) used as an assessment of clinical skills at the end of the first clinical year. Medical education. 2002;36:418-25.

19. McBride ME, Waldrop WB, Fehr JJ, Boulet JR, Murray DJ. Simulation in pediatrics: the reliability and validity of a multiscenario assessment. Pediatrics. 2011;128:335-43. 